JAMA | US Preventive Services Task Force | EVIDENCE REPORT

Folic Acid Supplementation for the Prevention of Neural Tube Defects

\title{
An Updated Evidence Report and Systematic Review for the US Preventive Services Task Force
}

Meera Viswanathan, PhD; Katherine A. Treiman, PhD; Julia Kish-Doto, PhD; Jennifer C. Middleton, PhD;

Emmanuel J. L. Coker-Schwimmer, MPH; Wanda K. Nicholson, MD

IMPORTANCE Neural tube defects are among the most common congenital anomalies in the United States. Periconceptional folic acid supplementation is a primary care-relevant preventive intervention.

OBJECTIVE Toreview the evidence on folic acid supplementation for preventing neural tube defects to inform the US Preventive Services Task Force for an updated Recommendation Statement.

DATA SOURCES MEDLINE, Cochrane Library, EMBASE, and trial registries through January 28, 2016, with ongoing surveillance through November 11, 2016; references; experts.

STUDY SELECTION English-language studies of folic acid supplementation in women. Excluded were poor-quality studies; studies of prepubertal girls, men, women without the potential for childbearing, and neural tube defect recurrence; and studies conducted in developing countries.

DATA EXTRACTION AND SYNTHESIS Two investigators independently reviewed abstracts, full-text articles, and risk of bias of included studies. One investigator extracted data and a second checked accuracy. Because of heterogeneity, data were not pooled.

MAIN OUTCOMES AND MEASURES Neural tube defects, harms of treatment (twinning, respiratory outcomes).

RESULTS A total of 24 studies $(\mathrm{N}>58860$ ) were included. In 1 randomized clinical trial from Hungary initiated in 1984, incidence of neural tube defects for folic acid supplementation compared with trace element supplementation was $0 \%$ vs $0.25 \%$ (Peto odds ratio [OR], 0.13 [95\% Cl, 0.03-0.65]; $\mathrm{n}=4862$ ). Odds ratios from cohort studies recruiting participants between 1984 and 1996 demonstrated beneficial associations and ranged from 0.11 to 0.27 ( $n=19982$ ). Three of 4 case-control studies with data from 1976 through 1998 reported ORs ranging from 0.6 to 0.7 ( $n>7121$ ). Evidence of benefit led to food fortification in the United States beginning in 1998, after which no new prospective studies have been conducted. More recent case-control studies drawing from data collected after 1998 have not demonstrated a protective association consistently with folic acid supplementation, with ORs ranging from 0.93 to 1.4 and confidence intervals spanning the null ( $n>13990)$. Regarding harms, 1 trial $(\mathrm{OR}, 1.40$ [95\% Cl, 0.89-2.21]; $\mathrm{n}=4767)$ and 1 cohort study $(\mathrm{OR}, 1.04[95 \% \mathrm{Cl}, 0.91-1.18] ; \mathrm{n}=2620)$ found no statistically significant increased risk of twinning. Three systematic reviews found no consistent evidence of increased risk of asthma (OR, 1.06 [95\% Cl, 0.99-1.14]; $\mathrm{n}=14438)$, wheezing, or allergy.

CONCLUSIONS AND RELEVANCE In studies conducted before the initiation of food fortification in the United States in 1998, folic acid supplementation provided protection against neural tube defects. Newer postfortification studies have not demonstrated a protective association but have the potential for misclassification and recall bias, which can attenuate the measured association of folic acid supplementation with neural tube defects.

JAMA. 2017;317(2):190-203. doi:10.1001/jama.2016.19193
Editorial page 144

Related article page 183

Supplemental content

CME Quiz at

jamanetworkcme.com

$+$

Related article at jamapediatrics.com
Author Affiliations: RTI International, Evidence-based Practice Center, University of North Carolina at Chapel Hill (Viswanathan, Treiman, Middleton, Coker-Schwimmer); RTI International, Research Triangle Park, North Carolina (Viswanathan, Kish-Doto); Cecil G. Sheps Center for Health Services Research, University of North Carolina at Chapel Hill (Middleton, Coker-Schwimmer); Department of Obstetrics and Gynecology, University of North Carolina at Chapel Hill (Nicholson).

Corresponding Author: Meera Viswanathan, PhD, RTI International, 3040 E Cornwallis Rd, Research Triangle Park, NC 27709

(viswanathan@rti.org). 
$\mathrm{N}$ eural tube defects (NTDs) are among the most common congenital anomalies in the United States. NTDs occur very early in the pregnancy, with limited or no chance for complete recovery. The Centers for Disease Control and Prevention estimated that the average annual prevalence of the 2 most common kinds of NTDs, anencephaly and spina bifida, was 6.5 per 10000 live births for the period from 2009 to 2011 . $^{.}$Prevention is an important medical intervention. Periconceptional folic acid supplementation is a primary prevention intervention that can be implemented in primary care settings.

In 2009, the US Preventive Services Task Force (USPSTF) recommended that all women planning a pregnancy or capable of pregnancy take a daily supplement containing 0.4 to $0.8 \mathrm{mg}$ of folic acid (A recommendation). To inform an updated recommendation, the evidence on benefits and harms of folic acid supplementation in populations relevant to US primary care was reviewed.

\section{Methods}

\section{Scope of the Review}

Detailed methods and contextual information (on current intake of folic acid from diet and other sources, effect of folic acid outside the periconceptional period, variation in benefits by risk factors, and supplementation benefits other than protection against neural tube defects) are available in the full evidence report available at https://www.uspreventiveservicestaskforce.org/Page/Document /final-evidence-review146/folic-acid-for-the-prevention-of -neural-tube-defects-preventive-medication. Figure1 shows the analytic framework and key questions (KQs) that guided the review.

\section{Data Sources and Searches}

We searched PubMed, the Cochrane Library, and EMBASE for English-language articles published from database inception through January 28, 2016. The search strategies for these databases are listed in the eMethods in the Supplement. Unpublished literature was searched for in ClinicalTrials.gov, HSRProj (Health Services Research Projects in Progress), the World Health Organization's International Clinical Trials Registry Platform, and NIH Reporter. To supplement electronic searches, the reference lists of pertinent articles and all suggested citations from peer reviewers were reviewed. Ongoing surveillance was conducted after January 2016 through article alerts and targeted searches of high-impact journals to identify major studies published in the interim that may affect the conclusions or understanding of the evidence and therefore the related USPSTF recommendation. The last surveillance was conducted on November 11, 2016.

\section{Study Selection}

Two investigators independently reviewed titles, abstracts, and fulltext articles using prespecified inclusion criteria for each KQ (eTable 1 in the Supplement).

Studies were included if they focused on the use of folic acid supplementation for the prevention of NTD-affected pregnancies in women of childbearing age. Not included were studies of prepubertal girls or men or women without the potential for childbearing (eg, postmenopausal, genetic, uterine, or ovarian abnormalities). We searched for studies that examined the use of folic acid supplementation with or without food fortification or naturally occurring folate for the prevention of NTDs. We also searched for studies that examined the supplementation of micronutrients (eg, multivitamin, iron) in combination with folic acid for the prevention of NTDs. For all KQs, we searched for studies conducted in the United States or in countries rated "very high" on the United Nations Human Development Index. ${ }^{3}$

Studies were included that compared interventions with placebo, no treatment, dietary supplementation only, supplementation with prenatal vitamins without folic acid, or iron supplements without folic acid for questions on benefits and harms and variations in subpopulations (KQs 1a, 1b, and 2a). Included studies

Figure 1. Analytic Framework and Key Questions

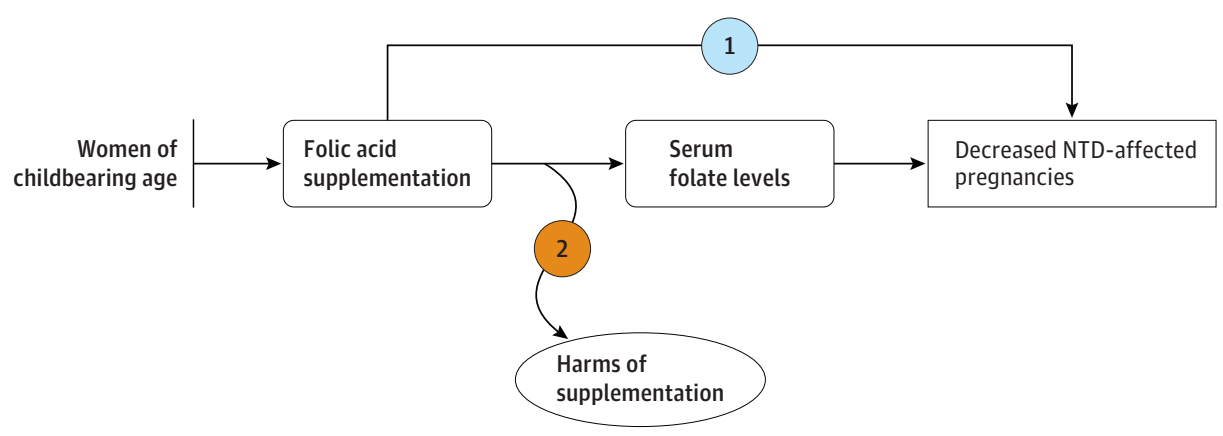

Key questions

1 a. To what extent does folic acid supplementation reduce the risk for neural tube defects (NTDs) (first occurrence) in women of childbearing age?

b. Does the effect of folic acid supplementation on NTDs (first occurrence) differ by race or ethnicity?

c. Do the benefits of folic acid supplementation differ by dosage, timing, or duration of therapy?

a. Are there harms associated with folic acid supplementation to the mother, fetus, neonate, or child?

b. Do the harms of folic acid supplementation differ by dosage, timing, or duration of therapy? 
compared interventions with lower or higher dose of folic acid supplementation only for questions about variations in benefits and harms by dosage (KQs $1 \mathrm{~b}, 1 \mathrm{c}$, and $2 \mathrm{~b}$ ).

Studies were sought that reported on the benefits of folic acid supplementation initiated before the index pregnancy or in the first trimester to prevent NTDs for questions on benefits and variation in benefits in subpopulations (KQs 1a and 1b). The timing of the intervention was expanded through the end of the pregnancy for questions on the effect of timing on benefits or any harms questions (KQs 1c, 2a, and 2b).

For benefits and harms (KQs 1 and 2), randomized clinical trials (RCTs), nonrandomized controlled trials, cohort studies, casecontrol studies, and systematic reviews were included. Additionally, for harms (KQs 2a and 2b), registry data were included.

Two reviewers dually reviewed the quality of all studies included in the 2009 report that met the inclusion criteria for the current review and resolved disagreement by discussion and consensus.

Data Extraction and Quality Assessment

For each included study, one investigator extracted information about methods, patient population, intervention, comparator, outcomes, timing, setting, and study design, and a second investigator reviewed for completeness and accuracy. Two independent investigators assessed the quality of each study as good, fair, or poor, using predefined criteria developed by the USPSTF and adapted for this topic (eTables 2, 3, 4, and 5 in the Supplement).

Disagreements were resolved by discussion and consensus. Issues leading to a judgment of poor quality included the risk of misclassification bias from retrospective recall of level and timing of exposure; the risk of selection bias from not identifying all cases of the outcome, including fetal deaths; and the risk of confounding from not appropriately accounting for factors such as infertility that might influence both exposure to folic acid supplementation and the outcome of twinning. Studies with 1 or more of these features were rated as poor quality. Other flaws that resulted in poor-quality ratings included initially assembled groups not close to being comparable or maintained throughout the study (including overall attrition of at least $20 \%$ or differential attrition of at least $15 \%$ between groups); use of unreliable or invalid measurement instruments or unequal application among groups (including not masking outcome assessment); and, for RCTs, the lack of intention-to-treat analysis.

Data Synthesis and Analysis

Findings for each KQ were qualitatively synthesized by summarizing the characteristics and results of included studies in tabular or narrative format. To determine whether meta-analyses were appropriate, the clinical and methodological heterogeneity (in population, interventions, and outcomes) of the studies were assessed following established guidance. ${ }^{4}$

\section{Results}

A total of 5786 titles and abstracts and 757 full-text articles were screened (Figure 2). Of the 32 good- or fair-quality articles on primary studies or systematic reviews, $20^{5-24}$ addressed KQ1a, $3^{6,7,20}$ addressed KQ1b, 8,7,17-22 addressed KQ1c, 20 8-13,15,23-35 addressed
KQ2a, and $6^{25-27,33,35,36}$ addressed KQ2b. Because of the heterogeneity across studies and over time, results were not pooled.

\section{Benefits of Folic Acid Supplementation}

Key Question 1a. To what extent does folic acid supplementation reduce the risk for NTDs (first occurrence) in women of childbearing age?

A total of 20 publications were found on the question of benefits of folic acid supplementation. Seven publications present results of the only eligible RCT. ${ }^{8-13,15}$ The study, conducted in Hungary, was an RCT initiated in 1984 and terminated in 1992, with information collected through 1993. Three publications relate to 2 cohort studies; one was a Hungarian cohort study of women recruited between 1993 and 1996, ${ }^{14}$ and the second was a cohort drawn from women who underwent a-fetoprotein screening or amniocentesis between 1984 and 1987. ${ }^{18,19}$ All other studies were case-control studies and compared infants having NTD-associated malformations with nonmalformed infants ${ }^{5-7,17,20,21}$ or with infants having non-NTDassociated malformations. ${ }^{16,22}$ Additionally, we checked the previous update to ensure that we had rereviewed and included all previously evaluated studies if they continued to meet inclusion criteria. ${ }^{23,24}$

These 20 publications, comprising 11 primary studies and 1 systematic review, ${ }^{23,24}$ drew from 8 data sources (Hungarian trial, ${ }^{8-13,15}$ Hungarian cohort, ${ }^{14}$ the New England study, ${ }^{18,19}$ the National Birth Defects Prevention Study, ${ }^{5,6}$ the Slone Birth Defects Study, ${ }^{716,22}$ the National Institute of Child Health and Human Development (NICHD) Neural Tube Defects Study, ${ }^{17}$ the California Birth Defects Monitoring Program, ${ }^{20}$ and the Texas Department of Health's Neural Tube Defect Project ${ }^{21}$ ). Together they span births occurring over 3 decades, from 1976 through 2007.

Although the RCT and the cohort studies potentially offer greater controls for potential sources of bias, they predate the 1998 regulations on mandatory food fortification in the United States. The casecontrol studies span a period ranging from 1976 through 2008, including several relying exclusively on data collected after food fortification. These 8 publications of case-control data draw from related, or in some cases subsets, of the same data.

Because study design, source of data, and secular changes in food fortification over time can all influence interpretation of study findings, results are presented first by study design, second by data source (presenting national or multistate ahead of 2-state or singlestate studies), and third by date of data collection for each publication for a data source.

\section{Evidence From Trials}

One RCT, described in 7 publications, ${ }^{8-13,15}$ randomized 5453 women in Hungary preconceptionally to a vitamin supplement containing folic acid or a trace-element supplement (Table 1). The trial reported no cases of NTDs in the experimental group and 6 cases in the control group (0\% vs 0.25\%; 25 fewer cases per 10000 [95\% $\mathrm{Cl}, 3-47$ fewer]; $P=.01$ by Fisher exact test; Peto odds ratio [OR], $0.13[95 \% \mathrm{Cl}, 0.03-0.65])$.

\section{Evidence From Cohort Studies}

At the conclusion of the RCT described above, no additional RCT was considered ethically possible because of the clear benefits of folic acid supplementation. The authors continued their investigation using the same intervention in a cohort of 6112 women drawn 
Figure 2. Literature Search Flow Diagram

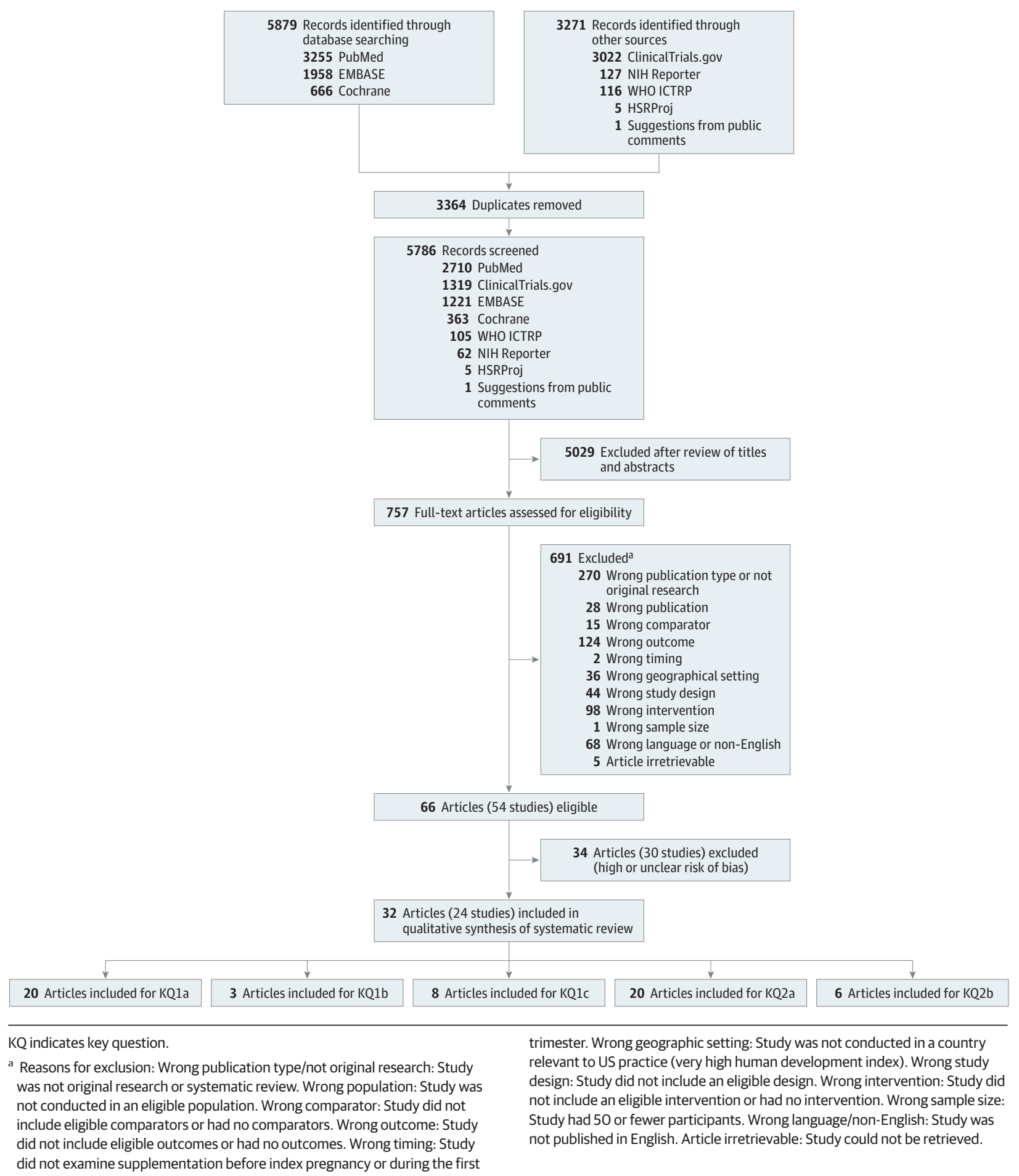

from the Hungarian Periconceptional Service (1993 to 1996), with supplementation provided before conception (Table 1). ${ }^{14}$ When compared with outcomes for unsupplemented pregnant women, the adjusted OR of an NTD-affected pregnancy for supplemented women was 0.11 (95\% Cl, 0.01-0.91; 0\% vs 0.29\%; 29 fewer cases per 10000 [95\% Cl, 9-50 fewer]). ${ }^{14}$ A cohort study of 23491 women in New England undergoing a-fetoprotein screening or amniocentesis between weeks 15 and 20 of gestation (1984 to 1987) defined exposure as the use of at least 1 multivitamin containing folic acid per week, between weeks 1 and 6 following conception (Table 2). Use of multivitamins containing folic acid was associated with an OR for NTD-affected pregnancy of 0.27 (95\% $\mathrm{Cl}, 0.11-0.63 ; 0.09 \%$ vs $0.35 \%, 26$ fewer cases per 10000 [95\% $\mathrm{Cl}, 4-47$ fewer]). ${ }^{18}$ 


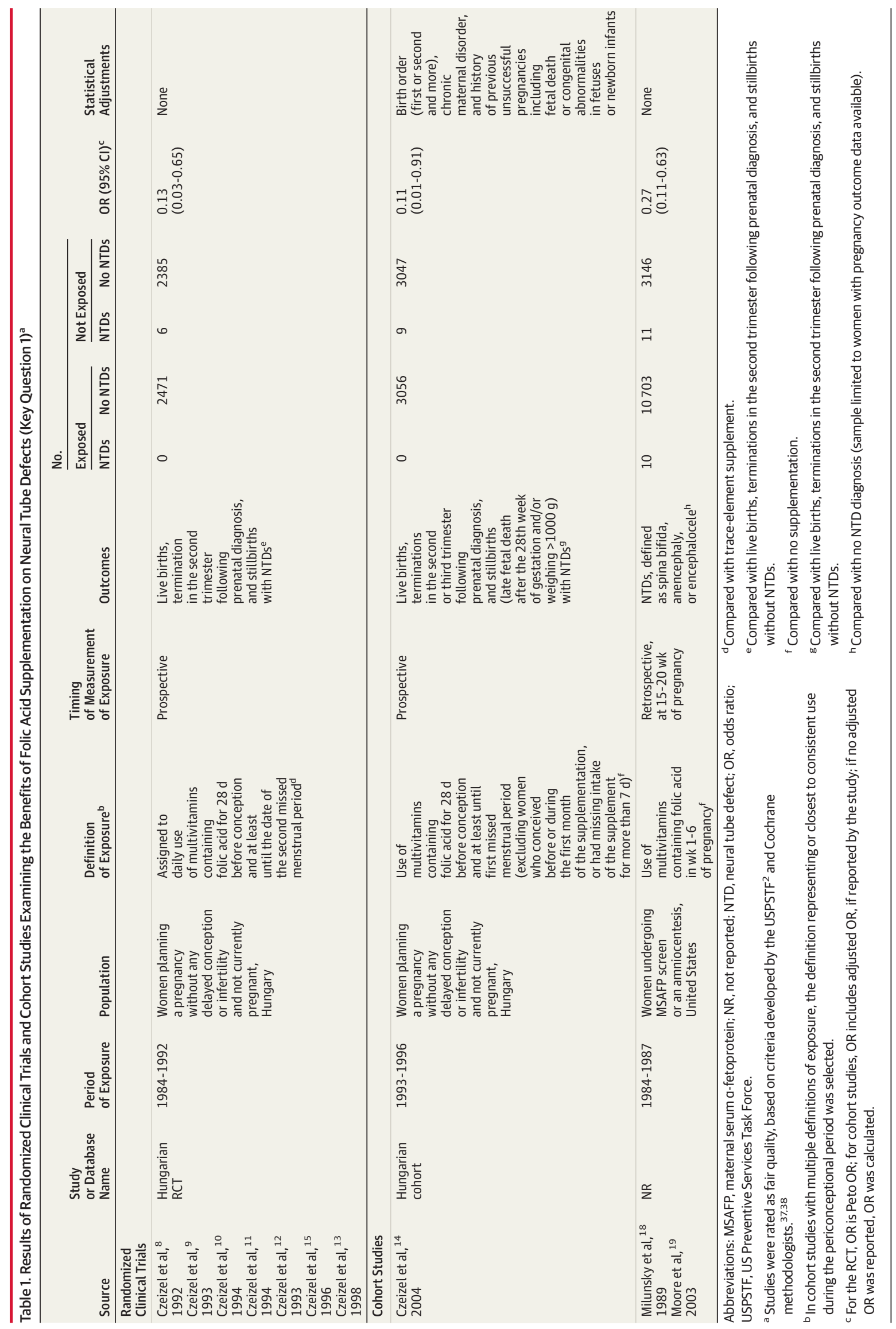




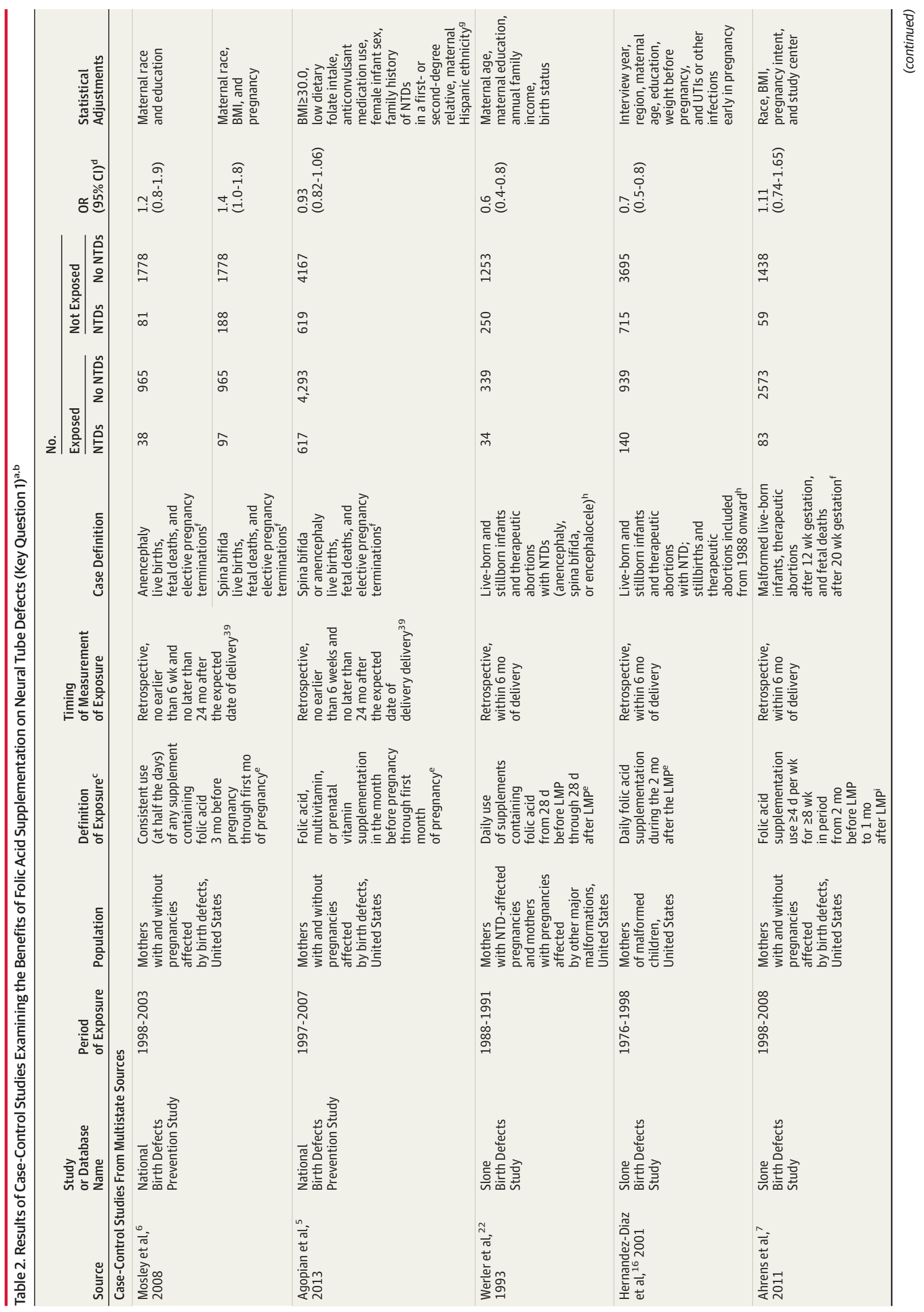




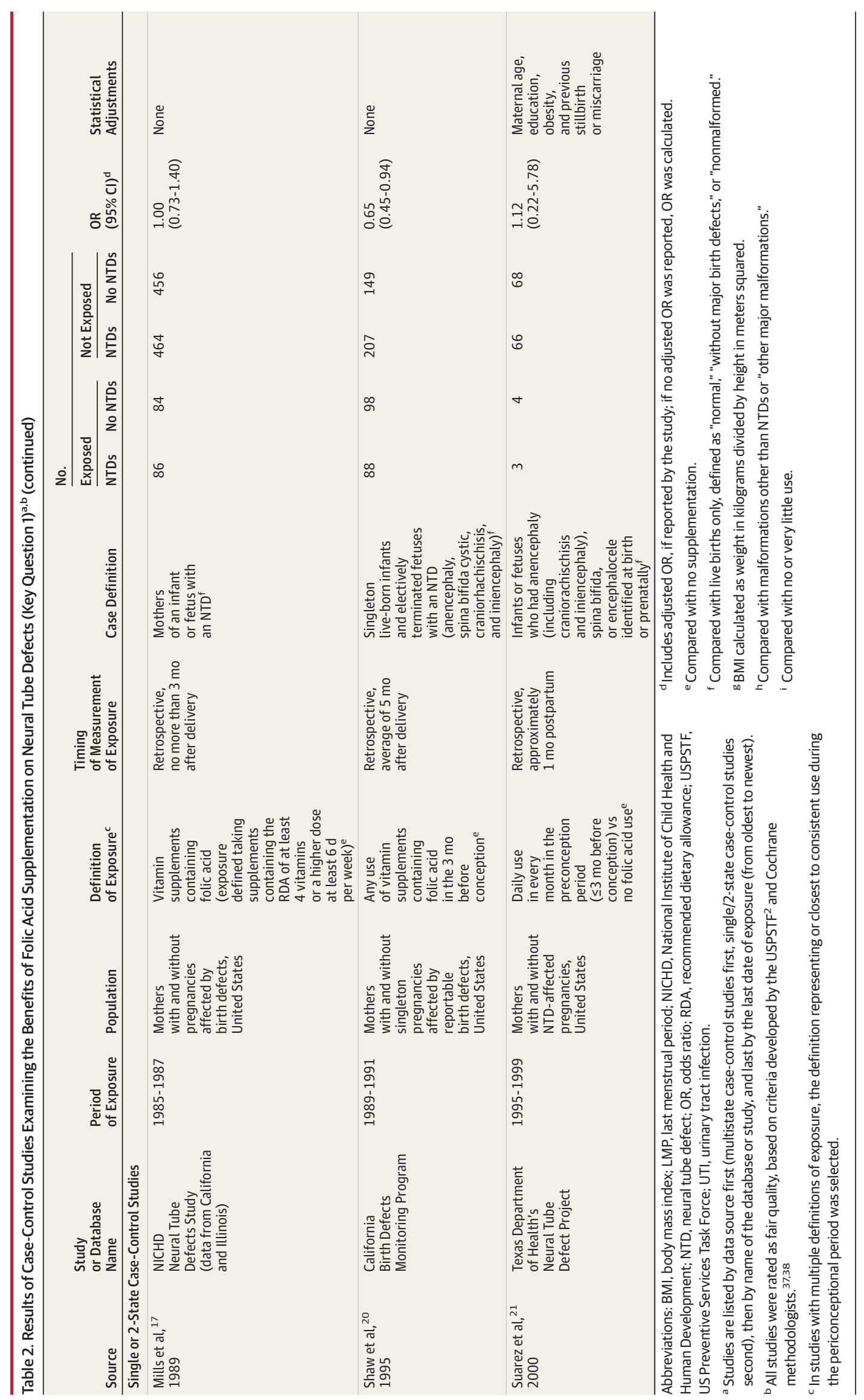


Evidence From Case-Control Studies

Case-control studies included multistate, 2-state, and single-state sources (Table 2). Two included publications used the National Birth Defects Prevention Study, ${ }^{5,6}$ which was established in 1997 and includes population-based birth defects surveillance systems in 10 sites. Eight of 10 surveillance sites include live births, fetal deaths, and elective pregnancy terminations, thus mitigating, but not entirely eliminating, the risk of selection bias. ${ }^{5}$ Women were asked to recall use of multivitamins or supplements from 3 months before pregnancy through the last month of pregnancy, resulting in a maximum recall period of 3 years. Both publications are consistent in demonstrating a lack of association of folic acid supplementation with benefits (adjusted OR for anencephaly and spina bifida, 0.93 [95\% $\mathrm{Cl}, 0.82-1.06]^{5}$; adjusted OR for anencephaly, $\left.1.2[95 \% \mathrm{Cl}, 0.8-1.9]^{5,6}\right)$.

Three included studies were based on data from the Slone Birth Defects Study and were published in $1993,{ }^{22} 2001,{ }^{16}$ and $2011 .{ }^{7}$ The Slone Birth Defects Study began in 1976. It identified cases, largely from hospital discharge records; randomly selected controls; and identified exposure to folic acid supplements through an interview conducted within 6 months of delivery going back to 6 months before pregnancy. Over the course of several decades, the list of included sites and sources changed. The definition of exposure varied by publication, and the period of recall ranged from 15 to 17 months. The 1993 and 2001 publications relied on data from the era before food fortification and consistently demonstrated that daily use of supplements was associated with a lower risk of NTDs compared with nonuse (adjusted OR of 0.7 [level of precision here and below as reported by authors] [95\% $\mathrm{Cl}, 0.5-0.8]$ in the 2001 study ${ }^{16}$; adjusted OR of 0.6 [95\% Cl, 0.4-0.8] in the 1993 study ${ }^{22}$ ). The 2011 Slone Birth Defects Study found no association of folic acid supplementation with the risk of spina bifida, regardless of the level of supplementation. ${ }^{7}$

Two other studies were conducted in the era before food fortification. Both studies drew on data from the California Birth Defects Monitoring program, using cases from 1985 to $1987^{17}$ and 1989 to $1991 .{ }^{20}$ One study additionally drew on data from Illinois (also from 1985 to 1987, the NICHD Neural Tube Defects Study). ${ }^{17}$ Recall periods ranged from 13 to 17 months. The NICHD Neural Tube Defects Study reported no association of supplements with NTDs (OR, 1.00 [95\% Cl, 0.73-1.40]; $P=.97) .{ }^{17}$ The study of California-only data found an OR of $0.65(95 \% \mathrm{Cl}, 0.45-0.94)$ for any use in the 3 months before conception. $^{20}$

One case-control study from a limited data source collected data from January 1995 to February 1999 from 148 Mexican American women living along the Texas-Mexico border with NTD-affected pregnancies and 158 control women with normal live births. ${ }^{21}$ The average period of recall for this study was 13 months. The study, spanning the eras before and after food fortification, found a nonsignificant protective OR for NTDs $(0.77$ [95\% Cl, 0.19-3.22]) in the subset of women taking multivitamins containing folic acid daily for 3 months or less prior to conception; when adjusted for maternal age, education, obesity, and previous stillbirth or miscarriage, the direction of effect altered (adjusted OR, 1.12 [95\% Cl, 0.22-5.78; $P$ value not reported).

Key Question 1b. Does the effect of folic acid supplementation on NTDs (first occurrence) differ by race or ethnicity?

Three case-control studies provide limited information about the effects of folic acid supplementation by racial and ethnic char- acteristics (eTable 6 in the Supplement). ${ }^{6,7,20}$ The Slone Birth Defects Study (1998 to 2008) found no positive association with periconceptional folic acid supplementation for white women and a possible increased risk of spina bifida among consistent supplement users of Hispanic ethnicity when compared with nonusers ${ }^{7}$; however, the authors note that this finding may be attributable to chance.

The National Birth Defects Prevention Study (1998 to 2003) found that periconceptional supplement use was not associated with a lower risk of having a pregnancy affected by an NTD, and there were no differences in the effects of folic acid supplementation by race or ethnicity. ${ }^{6}$ The California Birth Defects Monitoring Program Study found that women who used any folic acid-containing vitamin in the 3 months before conception had a lower risk of having an NTDaffected pregnancy. ${ }^{20}$ Reduction in risk for Hispanics was of smaller magnitude than that observed for non-Hispanic whites and blacks, but these results were not statistically significant and could have occurred because of chance.

Key Question 1c. Do the benefits of folic acid supplementation differ by dosage, timing, or duration of therapy?

One cohort study ${ }^{18,19}$ and 6 case-control studies ${ }^{6,7,17,20-22}$ provided information on the effects of dosage (eTable 7 in the Supplement) and timing (eTable 8 in the Supplement) of folic acid supplementation on NTDs. Four studies ( 1 cohort study ${ }^{19}$ and 3 case-control studies ${ }^{17,20,22}$ ) reported on dose of folic acid supplementation. Five studies ( 1 cohort study ${ }^{18}$ and 4 case-control studies $^{6,7,20,21}$ ) reported on timing of folic acid supplementation. All included studies on dose predate the food-fortification era ${ }^{17,19,20,22}$ and generally failed to find a dose-response effect. An exception was the Slone Birth Defects Study (1988 to 1991), ${ }^{22}$ which suggested lower odds of NTDs with daily use vs less than daily use (OR, 0.57 [95\% Cl, 0.35-0.93]). Older studies on timing consistently show no effect, whereas newer studies varied, with 1 study (postfortification) ${ }^{6}$ showing a protective association with use before pregnancy on anencephaly but not spina bifida and the other not finding a protective association for spina bifida. ${ }^{7}$

\section{Harms of Folic Acid Supplementation}

Key Question 2a. Are there harms associated with folic acid supplementation to the mother, fetus, neonate, or child?

One $\mathrm{RCT}^{11}$ and 1 cohort study ${ }^{31}$ provided information on twinning (Table 3). In a Hungarian trial comparing folic acid supplementation with a multivitamin to trace elements among informative pregnancies (defined as live births and stillbirths [late fetal deaths]), the proportion of twin pregnancies and twin births was not statistically significantly different between the 2 groups. Of the total pregnancies in the multivitamin group, $1.9 \%$ (46/2421) were determined to be twin gestations, compared with $1.4 \%$ (32/2346) of pregnancies in the trace element group (OR, 1.40 [95\% Cl, 0.89-2.21]; 54 more cases per 10000 [ $95 \% \mathrm{Cl}, 18$ fewer to 125 more]). The proportion of twin births (as opposed to pregnancies) was higher in the multivitamin group (93/2468 [3.8\%]) than in the trace element group (64/2378 [2.7\%]; OR, 1.41 [95\% Cl, 1.03-1.96]; 108 more cases per 10000 [ $95 \% \mathrm{Cl}, 8$ more to 207 more]). In a subgroup analysis of women receiving fertility drugs, the trial found no difference in twinning between the 2 groups. ${ }^{11}$ A prospective cohort study found an increased odds (baseline adjustment for maternal age and parity) of twinning among pregnancies with folate use compared with those 


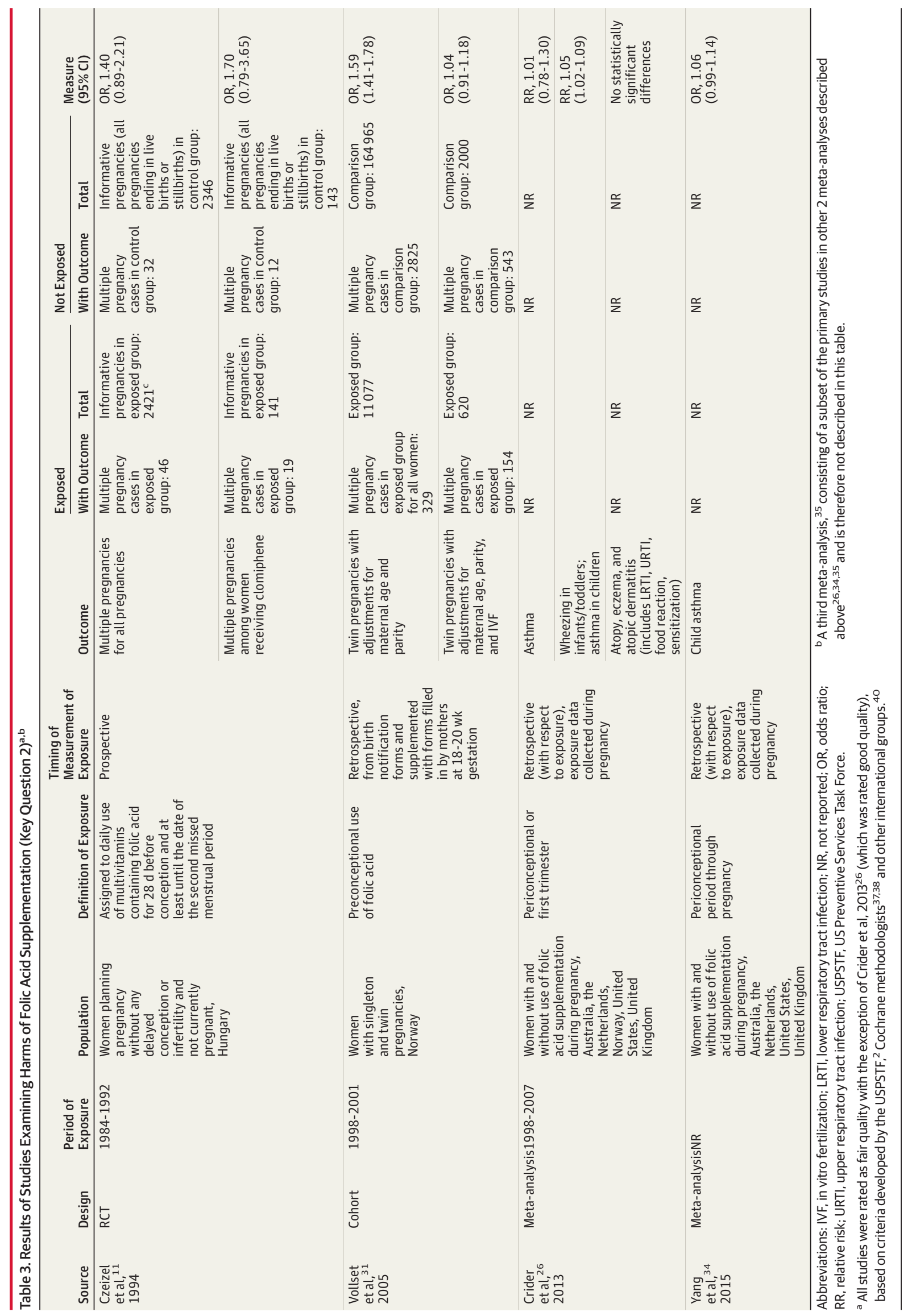


with no folate supplementation. ${ }^{31}$ With further adjustment for in vitro fertilization, the odds were attenuated and no longer statistically significant (1.04 [95\% Cl, 0.91-1.18]).

Eight articles ${ }^{25,27-30,32,33,36}$ synthesized in 3 systematic reviews ${ }^{26,34,35}$ reported on respiratory harms (childhood asthma or wheezing and allergen-related outcomes). All included primary studies were observational, with attendant risks of misclassification and recall bias. The pooled estimate from 1 meta-analysis ${ }^{26}$ focusing on the prepregnancy period through the first trimester ( $\mathrm{N}$ not reported) found no evidence from 3 studies ${ }^{29,30,32}$ of an association between maternal folic acid supplementation compared with no use and childhood asthma, with a pooled relative risk of $1.01(95 \% \mathrm{Cl}$, $\left.0.78-1.30 ; P=.95 ; P^{2}=0.00 ; P=.73\right) .{ }^{26} \mathrm{~A}$ second meta-analysis $(n=14438)^{34}$ included 5 studies ${ }^{25,29,30,32,33}$ and found no association between folic acid supplementation during the periconceptional period or pregnancy and the development of childhood asthma (OR, 1.06 [95\% Cl, 0.99-1.14]) but reported wide variations in the dose of folic acid supplementation across included studies. A third meta-analysis, ${ }^{35}$ consisting of a subset of the primary studies in other meta-analyses, also reported no statistically significant association of folic acid supplementation with asthma, wheezing, atopic dermatitis, eczema, and sensitization.

One trial ${ }^{13}$ also reported on potential adverse effects of folic acid supplementation, many of which are common pregnancy symptoms, such as weight gain, gastrointestinal symptoms, and rashes. The study found no statistically significant differences in the reporting of most of these symptoms between the 2 groups from before pregnancy through pregnancy confirmation.

Key Question 2b. Do the harms of folic acid supplementation differ by dosage, timing, or duration of therapy?

One study separated the study population into tertiles of folate taken as vitamin supplements $(<0.2 \mathrm{mg} / \mathrm{d}, 0.2$ to $0.499 \mathrm{mg} / \mathrm{d}$, and $\geq 0.5 \mathrm{mg} / \mathrm{d}$ ) and compared the second and third tertiles to the first for the incidence of any allergic disease, sensitization, recurrent wheezing, eczema, food reactions, IgE-mediated food allergy, and sensitization to food allergens (eTable 9 in the Supplement). All results had wide confidence intervals spanning or overlapping the line of no difference. ${ }^{36}$

Two of the cohort studies included in a previously published meta-analysis ${ }^{26}$ examined the association between prenatal use of a supplement containing folic acid (compared with no use) in the second or third trimester and asthma or wheezing in childhood (eTable 10 in the Supplement). ${ }^{25,27}$ Of the 15 associations evaluated across 2 studies, only 1 association was significantly increased (adjusted prevalence ratio for maternal report of wheezing at 1 year, 1.20 [95\% Cl, 1.04-1.39]). ${ }^{25}$ Three cohort studies examined the use of supplements containing folic acid during the second or third trimester and risk of other allergic outcomes. ${ }^{25,27,33}$ The metaanalysis reported no significant findings in 38 reported associations across these 3 studies. ${ }^{26}$

A meta-analysis examined the incidence of asthma and wheezing by timing of supplementation (prepregnancy, early pregnancy, other period in pregnancy). ${ }^{35}$ Four of 5 reported associations showed no statistically significant association of folic acid supplementation with asthma or wheezing in childhood. The 1 statistically significant association with wheezing in childhood was associated with exposure in early pregnancy (relative risk, $1.06[95 \% \mathrm{Cl}, 1.02-1.09])^{27-29}$

\section{Discussion}

A summary of findings in this evidence review is found in Table 4 and Table 5. Most of the studies included in this review have broad eligibility criteria; their participants are representative of the US primary care population. Early studies (1 trial, cohort and case-control studies) provided consistent evidence of benefit. After the publication of the Hungarian trial and other trials in women with recurrent NTDs (not included in this review), the evidence of benefit pointed to the need for large-scale public health interventions; the United States initiated the addition of folate to grain products in $1998 .{ }^{41}$ The evidence of benefit also made the conduct of additional trials unethical. As a consequence, all subsequent studies relied on observational data using case-control designs. These case-control studies do not show a protective association.

There was no consistent evidence of variation in benefits for subpopulations or by dose or timing. There was also no consistent evidence of an increased risk of twinning or childhood respiratory illnesses or variation in these outcomes by timing or dose.

Although the effect of food fortification may explain lack of benefit in more recent studies, study design flaws and inadequate sample size in these studies are also important considerations. All included observational studies in this review contain inherent and unavoidable sources of bias. Prospective cohort studies may not be able to ascertain all NTD cases. Retrospective studies have a risk of recall bias. In the case-control studies included in this review, women were asked to recall frequency and dose of supplements over a relatively short period of exposure (around the time of conception) occurring between 13 months and 3 years prior to the interview. Both of the risks of bias described above (case ascertainment and recall) will reduce the differences between study groups. The relative rarity of the outcome and the difficulty of adequately powering studies also complicates the interpretation of the results.

An additional consideration in weighing the relative contributions of folic acid supplementation and food fortification is the extent of benefit provided by food fortification. Estimates of folate sufficiency of intake vary widely by measure. When the highest threshold, the recommended usual intake of $0.4 \mathrm{mg} / \mathrm{d}$, is used, National Health and Nutrition Examination Survey data from 2003 to 2006 suggest that $76 \%$ of nonpregnant women aged 15 to 44 years did not consume the recommended daily intake. Among all women, the median intake of folic acid overall was $0.245 \mathrm{mg} / \mathrm{d} .{ }^{42}$ The proportion of women not consuming the recommended usual intake varies from 70 to $91 \%$ by race and ethnicity.

Rather than using a daily 400- $\mu$ g dosage to define adequate intake, another approach is to set the threshold for insufficiency based on red blood cell folate concentrations. A threshold of $400 \mathrm{ng} / \mathrm{mL}$ ( $906 \mathrm{nmol} / \mathrm{L})$ or more is based on an association of the threshold with an NTD prevalence of more than 9 per 10000 live births. This threshold yields an estimate suggesting a lower level of insufficiency, on average, with $22.8 \%$ of nonpregnant women aged 12 to 49 years having suboptimal red blood cell folate concentrations for NTD prevention. ${ }^{43}$ Levels vary by use of dietary supplements containing folic acid, consumption of man- 


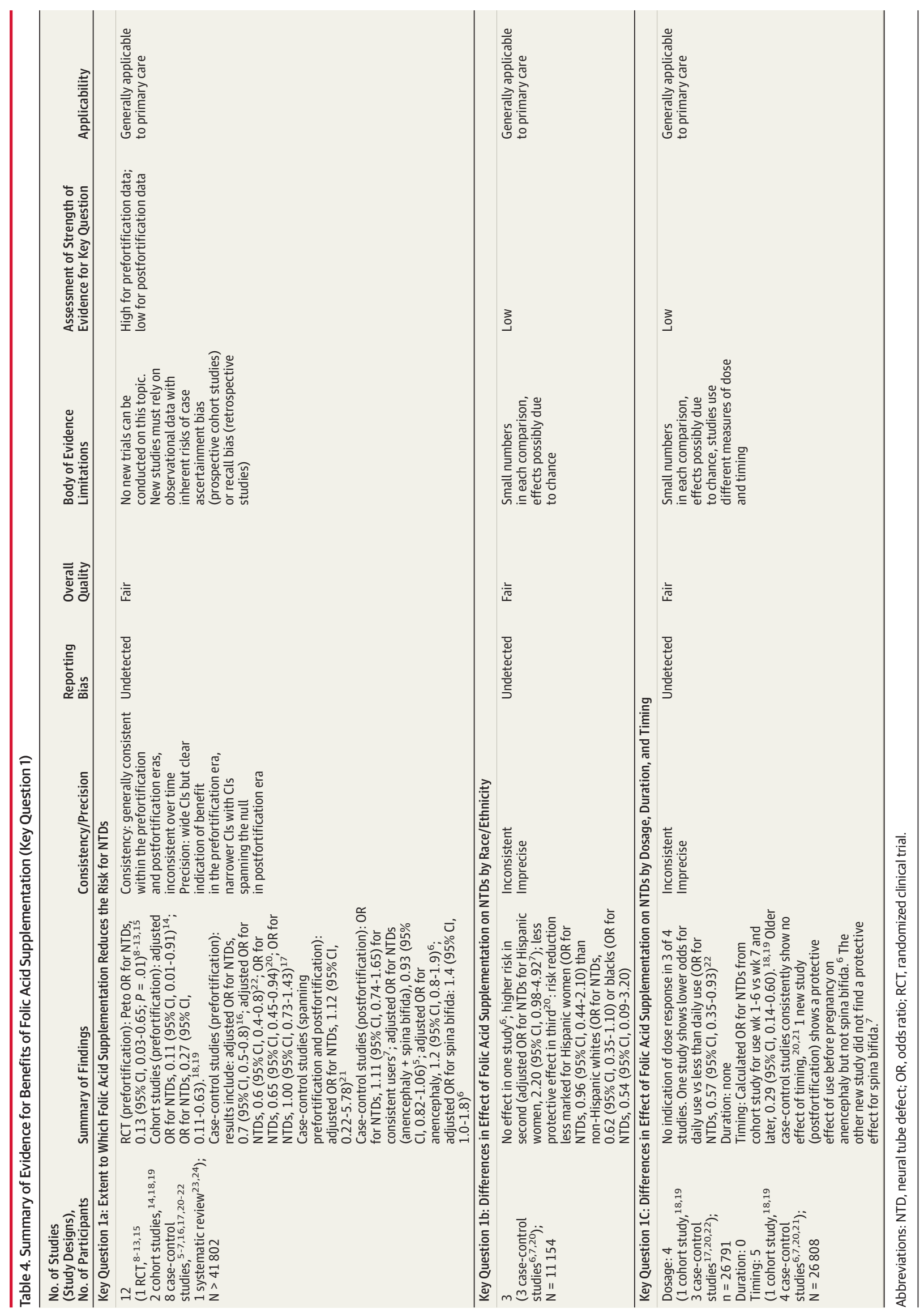




\begin{tabular}{|c|c|c|c|c|c|c|c|}
\hline $\begin{array}{l}\text { No. of Studies } \\
\text { (Study Designs) }\end{array}$ & Summary of Findings & Consistency/Precision & $\begin{array}{l}\text { Reporting } \\
\text { Bias }\end{array}$ & $\begin{array}{l}\text { Overall } \\
\text { Quality }\end{array}$ & $\begin{array}{l}\text { Body of } \\
\text { Evidence } \\
\text { Limitations }\end{array}$ & $\begin{array}{l}\text { Assessment } \\
\text { of Strength of Evidence } \\
\text { for Key Question }\end{array}$ & Applicability \\
\hline \multicolumn{8}{|c|}{ Key Question 2a: Harms Associated With Folic Acid Supplementation } \\
\hline $\begin{array}{l}\text { Twinning in } \\
\text { women: } 2 \\
\left(1 \text { trial, }^{11}\right. \\
\left.1 \text { cohort }^{31}\right) \\
\mathrm{N}=7387\end{array}$ & $\begin{array}{l}\text { The trial found no } \\
\text { statistically } \\
\text { significant } \\
\text { differences in twin } \\
\text { pregnancy rate (OR } \\
\text { for twin pregnancy, } \\
1.40\left(95 \% \mathrm{Cl}^{1}\right. \\
0.89-2.21){ }^{11} \text { The } \\
\text { cohort study }{ }^{11} \text { found } \\
\text { that the higher risk of } \\
\text { twin birth for folic } \\
\text { acid supplementation } \\
\text { use (OR for twin } \\
\text { birth, } 1.59 \text { [ } 95 \% \mathrm{Cl} \text {, } \\
1.41-1.78]) \text { was } \\
\text { attenuated once } \\
\text { potential } \\
\text { misclassification was } \\
\text { accounted for (1.04 } \\
\text { [95\% Cl, } \\
0.91-1.18])^{31}\end{array}$ & $\begin{array}{l}\text { Consistent } \\
\text { Imprecise }\end{array}$ & Undetected & Fair & $\begin{array}{l}\text { Low event rate, } \\
\text { wide Cls }\end{array}$ & $\begin{array}{l}\text { Moderate } \\
\text { for no effect }\end{array}$ & $\begin{array}{l}\text { Generally } \\
\text { applicable to } \\
\text { primary care }\end{array}$ \\
\hline $\begin{array}{l}\text { Childhood } \\
\text { asthma, } \\
\text { wheezing, } \\
\text { allergy: } 11 \\
\text { ( } 3 \text { systematic } \\
\text { reviews, } 26,34,35 \\
8 \\
\text { observational } \\
\text { studies } 25,27-30,32 \\
\mathrm{~N}>14438\end{array}$ & $\begin{array}{l}\text { No effect for a large } \\
\text { majority of } \\
\text { comparisons and } \\
\text { outcomes }^{25-30,32-36} \\
2,33,36)\end{array}$ & $\begin{array}{l}\text { Consistent } \\
\text { Precise }\end{array}$ & Undetected & & $\begin{array}{l}\text { Variable } \\
\text { measures of } \\
\text { outcomes and } \\
\text { exposure, all } \\
\text { observation } \\
\text { studies with } \\
\text { risks of bias } \\
\text { from case } \\
\text { ascertainment } \\
\text { and recall }\end{array}$ & $\begin{array}{l}\text { Moderate } \\
\text { for no effect }\end{array}$ & $\begin{array}{l}\text { Generally } \\
\text { applicable to } \\
\text { primary care }\end{array}$ \\
\hline $\begin{array}{l}\text { Other adverse } \\
\text { events in } \\
\text { women: } 1 \\
\left(1 \mathrm{RCT}^{13}\right) \\
\mathrm{N}=4862)\end{array}$ & $\begin{array}{l}\text { Increased risk for } \\
\text { weight gain, } \\
\text { diarrhea, } \\
\text { constipation; reduced } \\
\text { risk for irregular } \\
\text { defecation; no } \\
\text { difference for } \\
\text { increased appetite, } \\
\text { lack of appetite, } \\
\text { exanthema, } \\
\text { heartburn, and } \\
\text { vertigo }^{13}\end{array}$ & $\begin{array}{l}\text { Consistency unknown, } \\
\text { single study, imprecise }\end{array}$ & Undetected & & $\begin{array}{l}\text { Low event rate, } \\
\text { wide Cls }\end{array}$ & $\begin{array}{l}\text { Low } \\
\text { for no effect }\end{array}$ & $\begin{array}{l}\text { Generally } \\
\text { applicable to } \\
\text { primary care }\end{array}$ \\
\hline \multicolumn{8}{|c|}{ Key Question 2b: Differences in Harms Associated With Folic Acid Supplementation by Dosage, Timing, and Duration } \\
\hline $\begin{array}{l}\text { Dosage: } 2 \\
\text { (1 systematic } \\
\text { review, }{ }^{26} \\
1 \\
\text { observational } \\
\text { study }{ }^{36} \text { ); } \\
\mathrm{N}=484 \\
\text { Duration: } 0 \\
\text { Timing of } \\
\text { asthma, } \\
\text { wheezing, } \\
\text { allergy: } 5 \\
(2 \text { systematic } \\
\text { reviews, } \\
3 \\
\text { observational } \\
\text { studies } 25,27,33 \text {; } \\
\text { No. varies by } \\
\text { outcome }\end{array}$ & $\begin{array}{l}\text { Dosage: no } \\
\text { consistent increase in } \\
\text { the risk of childhood } \\
\text { asthma, wheezing, or } \\
\text { allergies by } \\
\text { dosage } \\
\text { Duration: none } \\
\text { Timing: no consistent } \\
\text { increase in the risk of } \\
\text { childhood asthma, } \\
\text { wheezing, or } \\
\text { allergies by } \\
\text { timing }^{25-27,33,35}\end{array}$ & $\begin{array}{l}\text { Consistent } \\
\text { Precise }\end{array}$ & Undetected & & $\begin{array}{l}\text { Variable } \\
\text { measures of } \\
\text { outcomes and } \\
\text { exposure, all } \\
\text { observation } \\
\text { studies with } \\
\text { risks of bias } \\
\text { from case } \\
\text { ascertainment } \\
\text { and recall }\end{array}$ & $\begin{array}{l}\text { Low } \\
\text { for no effect }\end{array}$ & $\begin{array}{l}\text { Generally } \\
\text { applicable to } \\
\text { primary care }\end{array}$ \\
\hline
\end{tabular}
outcome

Abbreviations: NTD, neural tube defect; OR, odds ratio; RCT, randomized clinical trial.

datorily fortified enriched cereal grain products as the only source of folic acid, non-Hispanic black or Hispanic race and ethnicity, and current smoking status.

Very few women exceed the upper level for folic acid consumption $(1000 \mu \mathrm{g} / \mathrm{d})$. According to the 2015 Dietary Guideline Advisory Committee report, less than $3 \%$ of women aged 14 to 50 years were getting more than $1000 \mu \mathrm{g} / \mathrm{d}$ from food, bever- ages, and dietary supplements, based on National Health and Nutrition Examination Study data collected from 2007-2010. 44

The limitations of this review arise from its scope and the limitations of the evidence. As with the previous USPSTF review on this topic, ${ }^{23,24}$ interventions were restricted to folic acid supplementation and did not evaluate the effectiveness of food fortification, counseling to increase dietary intake, or screening for NTDs. The review 
did not examine the effects of folic acid supplementation on benefits other than averted NTDs. In addition, it did not evaluate systematically the effect of folic acid supplementation among high-risk populations such as women with previous pregnancies with NTDs.

Limitations of the evidence relate to insufficient data and the quality of evidence as a whole. There was very limited information on differences in benefits and risks of folic acid supplementation by race, ethnicity, dose, and timing and no information on duration. Regarding the overall quality of evidence, ethical considerations limit the conduct of RCTs for this question.

\section{Conclusions}

In studies conducted before the initiation of food fortification in the United States in 1998, folic acid supplementation provided protection against neural tube defects. Newer postfortification studies have not demonstrated a protective association but have the potential for misclassification and recall bias, which can attenuate the measured association of folic acid supplementation with neural tube defects.

\section{ARTICLE INFORMATION}

Author Contributions: Dr Viswanathan had full access to all of the data in the study and takes responsibility for the integrity of the data and the accuracy of the data analysis.

Concept and design: Viswanathan, Treiman, Nicholson.

Acquisition, analysis, or interpretation of data:

Viswanathan, Treiman, Middleton, Coker-

Schwimmer, Nicholson.

Drafting of the manuscript: Viswanathan, Treiman, Middleton, Nicholson.

Critical revision of the manuscript for important intellectual content: Viswanathan, CokerSchwimmer, Nicholson.

Statistical analysis: Viswanathan, Nicholson. Obtained funding: Viswanathan.

Administrative, technical, or material support: Viswanathan, Treiman, PhD, Middleton.

Supervision: Viswanathan.

Conflict of Interest Disclosures: All authors have completed and submitted the ICMJE Form for Disclosure of Potential Conflicts of Interest and none were reported.

Funding/Support: This research was funded under contract HHSA-290-2012-00015i, Task Order No. 4, from the Agency for Healthcare Research and Quality (AHRQ), US Department of Health and Human Services, under a contract to support the USPSTF.

Role of the Funder/Sponsor: Investigators worked with USPSTF members and AHRQ staff to develop the scope, analytic framework, and key questions for this review. AHRQ had no role in study selection, quality assessment, or synthesis. AHRQ staff provided project oversight; reviewed the report to ensure that the analysis met methodological standards; and distributed the draft for peer review. Otherwise, AHRQ had no role in the conduct of the study; collection, management, analysis, and interpretation of the data; and preparation, review, or approval of the manuscript findings. The opinions expressed in this document are those of the authors and do not reflect the official position of AHRQ or the US Department of Health and Human Services.

Additional Contributions: We gratefully acknowledge the following individuals for their contributions to this project, including AHRQ Staff (Iris Mabry-Hernandez, MD, MPH, and Tracy Wolff, MD, MPH), Kaiser Permanente Research Affiliates Evidence-based Practice Center (EPC) Staff (Evelyn Whitlock, MD, MPH), RTI International-University of North Carolina EPC Staff (Kathleen N. Lohr, PhD; Carol Woodell, BA; Christiane Voisin, MSLS; Sharon Barrell, MA; and Loraine Monroe). The USPSTF members, expert consultants, peer reviewers, and federal partner reviewers did not receive financial compensation for their contributions. Dr Lohr and Mss Woodell, Voisin, and Barrell received compensation for their role in this project.

Additional Information: A draft version of the ful evidence report underwent external peer review from 5 content experts (Nancy Chescheir, MD [University of North Carolina at Chapel Hill]; Anna Maria Siega-Riz, PhD [University of North Carolina at Chapel Hill]; Kimberly D. Gregory, MD, MPH [Cedars-Sinai, Los Angeles, California]; Joe Leigh Simpson, MD, FRCOG [March of Dimes Foundation, White Plains, New York]; Lt Col. Catherine Witkop, MD, MPH [Uniformed Services University, Bethesda, Maryland]) and 8 federal partner reviewers from the National Institute of Environmental Health Sciences, Eunice Kennedy Shriver National Institute of Child Health and Human Development, National Center on Birth Defects and Developmental Disabilities (Centers for Disease Control and Prevention). Comments from reviewers were presented to the USPSTF during its deliberation of the evidence and were considered in preparing the final evidence review.

Editorial Disclaimer: This evidence report is presented as a document in support of the accompanying USPSTF Recommendation Statement. It did not undergo additional peer review after submission to JAMA.

\section{REFERENCES}

1. Williams J, Mai CT, Mulinare J, et al; Centers for Disease Control and Prevention. Updated estimates of neural tube defects prevented by mandatory folic acid fortification-United States, 1995-2011. MMWR Morb Mortal Wkly Rep. 2015;64(1):1-5.

2. Harris RP, Helfand M, Woolf $\mathrm{SH}$, et al; Methods Work Group, Third US Preventive Services Task Force. Current methods of the US Preventive Services Task Force: a review of the process. Am J Prev Med. 2001;20(3)(suppl):21-35.

3. United Nations Development Programme (UNDP). Human Development Report 2015 http://hdr.undp.org/sites/default/files/2015 human_development_report.pdf. 2015. Accessed June 22, 2016

4. West SL, Gartlehner G, Mansfield AJ, et al. Comparative Effectiveness Review Methods: Clinical Heterogeneity. Rockville, MD: Agency for Healthcare Research and Quality; 2010. AHRQ publication 10-EHCO7O-EF.

5. Agopian AJ, Tinker SC, Lupo PJ, Canfield MA, Mitchell LE; National Birth Defects Prevention Study. Proportion of neural tube defects attributable to known risk factors. Birth Defects Res A Clin Mol Teratol. 2013;97(1):42-46.
6. Mosley BS, Cleves MA, Siega-Riz AM, et al; National Birth Defects Prevention Study. Neural tube defects and maternal folate intake among pregnancies conceived after folic acid fortification in the United States. Am J Epidemiol. 2009;169(1): 9-17.

7. Ahrens K, Yazdy MM, Mitchell AA, Werler MM. Folic acid intake and spina bifida in the era of dietary folic acid fortification. Epidemiology. 2011; 22(5):731-737.

8. Czeizel AE, Dudás I. Prevention of the first occurrence of neural-tube defects by periconceptional vitamin supplementation. N Engl J Med. 1992:327(26):1832-1835.

9. Czeizel AE. Prevention of congenital abnormalities by periconceptional multivitamin supplementation. BMJ. 1993;306(6893):1645-1648.

10. Czeizel AE, Dudás I, Métneki J. Pregnancy outcomes in a randomised controlled trial of periconceptional multivitamin supplementation: final report. Arch Gynecol Obstet. 1994;255(3):131139.

11. Czeizel AE, Métneki J, Dudás I. The higher rate of multiple births after periconceptional multivitamin supplementation: an analysis of causes. Acta Genet Med Gemellol (Roma). 1994;43 (3-4):175-184

12. Czeizel AE. Controlled studies of multivitamin supplementation on pregnancy outcomes. Ann N Y Acad Sci. 1993;678:266-275.

13. Czeizel AE. Periconceptional folic acid containing multivitamin supplementation. Eur J Obstet Gynecol Reprod Biol. 1998;78(2):151-161.

14. Czeizel $A E$, Dobó $M$, Vargha P. Hungarian cohort-controlled trial of periconceptional multivitamin supplementation shows a reduction in certain congenital abnormalities. Birth Defects Res A Clin Mol Teratol. 2004;70(11):853-861.

15. Czeizel AE. Reduction of urinary tract and cardiovascular defects by periconceptional multivitamin supplementation. Am J Med Genet. 1996;62(2):179-183.

16. Hernández-Díaz S, Werler MM, Walker AM, Mitchell AA. Neural tube defects in relation to use of folic acid antagonists during pregnancy. Am J Epidemiol. 2001;153(10):961-968.

17. Mills JL, Rhoads GG, Simpson JL, et al; National Institute of Child Health and Human Development Neural Tube Defects Study Group. The absence of a relation between the periconceptional use of vitamins and neural-tube defects. N Engl J Med. 1989;321(7):430-435.

18. Milunsky A, Jick H, Jick SS, et al. Multivitamin/folic acid supplementation in early 
pregnancy reduces the prevalence of neural tube defects. JAMA. 1989;262(20):2847-2852.

19. Moore LL, Bradlee ML, Singer MR, Rothman KJ, Milunsky A. Folate intake and the risk of neural tube defects: an estimation of dose-response. Epidemiology. 2003;14(2):200-205.

20. Shaw GM, Schaffer D, Velie EM, Morland K, Harris JA. Periconceptional vitamin use, dietary folate, and the occurrence of neural tube defects. Epidemiology. 1995;6(3):219-226.

21. Suarez L, Hendricks KA, Cooper SP, Sweeney AM, Hardy RJ, Larsen RD. Neural tube defects among Mexican Americans living on the US-Mexico border: effects of folic acid and dietary folate. Am J Epidemiol. 2000;152(11):1017-1023.

22. Werler MM, Shapiro S, Mitchell AA. Periconceptional folic acid exposure and risk of occurrent neural tube defects. JAMA. 1993;269(10) 1257-1261.

23. Wolff T, Witkop CT, Miller T, Syed SB. Folic Acid Supplementation for the Prevention of Neural Tube Defects: An Update of the Evidence for the US Preventive Services Task Force. Rockville, MD: Agency for Healthcare Research and Quality; 2009.

24. Wolff T, Witkop CT, Miller T, Syed SB; US Preventive Services Task Force. Folic acid supplementation for the prevention of neural tube defects: an update of the evidence for the US Preventive Services Task Force. Ann Intern Med. 2009;150(9):632-639.

25. Bekkers MB, Elstgeest LE, Scholtens S, et al. Maternal use of folic acid supplements during pregnancy, and childhood respiratory health and atopy. Eur Respir J. 2012;39(6):1468-1474.

26. Crider KS, Cordero AM, Qi YP, Mulinare J, Dowling NF, Berry RJ. Prenatal folic acid and risk of asthma in children: a systematic review and meta-analysis. Am J Clin Nutr. 2013;98(5):1272-1281.

27. Håberg SE, London SJ, Stigum $H$, Nafstad $P$, Nystad W. Folic acid supplements in pregnancy and early childhood respiratory health. Arch Dis Child. 2009;94(3):180-184.
28. Kiefte-de Jong JC, Timmermans S, Jaddoe VW, et al. High circulating folate and vitamin B-12 concentrations in women during pregnancy are associated with increased prevalence of atopic dermatitis in their offspring. J Nutr. 2012;142(4): 731-738.

29. Magdelijns FJ, Mommers M, Penders J, Smits L, Thijs $C$. Folic acid use in pregnancy and the development of atopy, asthma, and lung function in childhood. Pediatrics. 2011;128(1):e135-e144.

30. Martinussen MP, Risnes KR, Jacobsen GW, Bracken MB. Folic acid supplementation in early pregnancy and asthma in children aged 6 years. Am J Obstet Gynecol. 2012;206(1):72.

31. Vollset SE, Gjessing HK, Tandberg A, et al. Folate supplementation and twin pregnancies. Epidemiology. 2005;16(2):201-205.

32. Whitrow MJ, Moore VM, Rumbold AR, Davies MJ. Effect of supplemental folic acid in pregnancy on childhood asthma: a prospective birth cohort study. Am J Epidemiol. 2009;170(12):1486-1493.

33. Granell R, Heron J, Lewis S, Davey Smith G, Sterne JA, Henderson J. The association between mother and child MTHFR C677T polymorphisms, dietary folate intake and childhood atopy in a population-based, longitudinal birth cohort [published correction appears in Clin Exp Allergy. 2008;38(4):699]. Clin Exp Allergy. 2008;38(2): 320-328.

34. Yang $L$, Jiang $L$, Bi $M$, et al. High dose of maternal folic acid supplementation is associated to infant asthma. Food Chem Toxicol. 2015;75:88-93.

35. Wang $T$, Zhang HP, Zhang $X$, Liang ZA, Ji YL, Wang $\mathrm{G}$. Is folate status a risk factor for asthma or other allergic diseases? Allergy Asthma Immunol Res. 2015;7(6):538-546.

36. Dunstan JA, West C, McCarthy S, et al. The relationship between maternal folate status in pregnancy, cord blood folate levels, and allergic outcomes in early childhood. Allergy. 2012;67(1): 50-57.
37. Sterne JAC, Hernán MA, Reeves BC, et al. ROBINS-I: a tool for assessing risk of bias in non-randomized studies of interventions. BMJ. 2016;355:i4919.

38. Higgins JP, Altman DG, Gøtzsche PC, et al; Cochrane Bias Methods Group; Cochrane Statistical Methods Group. The Cochrane Collaboration's tool for assessing risk of bias in randomised trials. BMJ. 2011;343:d5928.

39. Yoon PW, Rasmussen SA, Lynberg MC, et al. The National Birth Defects Prevention Study. Public Health Rep. 2001;116(suppl 1):32-40.

40. Whiting P, Savović J, Higgins JP, et al; ROBIS Group. ROBIS: a new tool to assess risk of bias in systematic reviews was developed. J Clin Epidemiol. 2016;69:225-234.

41. US Department of Health and Human Services. Food standards: amendment of standards of identity for enriched grain products to require addition of folic acid. Fed Regist. 1996;61(44):87818797.

42. Tinker SC, Cogswell ME, Devine O, Berry RJ. Folic acid intake among U.S. women aged 15-44 years, National Health and Nutrition Examination Survey, 2003-2006. Am J Prev Med. 2010;38(5): 534-542.

43. Tinker SC, Hamner HC, Qi YP, Crider KS. U.S. women of childbearing age who are at possible increased risk of a neural tube defect-affected pregnancy due to suboptimal red blood cell folate concentrations, National Health and Nutrition Examination Survey 2007 to 2012. Birth Defects Res A Clin Mol Teratol. 2015;103(6):517-526.

44. Dietary Guidelines Advisory Committee. Scientific Report of the 2015 Dietary Guidelines Advisory Committee: Advisory Report to the Secretary of Health and Human Services. Rockville, MD: US Departments of Health and Human Services (HHS) and Agriculture (USDA); 2015. 